\title{
Chapter 5 \\ Navigating the Cultural Interface \\ to Develop a Model for Dentistry \\ Education: Cultural Competence \\ Curricula in Dentistry Education
}

\section{Cathryn Forsyth, Stephanie D. Short, Michelle Irving, Marc Tennant, and John Gilroy}

\begin{abstract}
Indigenous people in Australia experience a greater burden of dental and oral disease than non-Indigenous Australians. Cultural competence of the dental team is crucial in the delivery of oral health services in addressing these health disparities. Higher education institutions across Australia are required to incorporate Indigenous culture into their curricula to improve educational outcomes for Indigenous peoples and to increase cultural competence of staff and students. A research team of Indigenous and non-Indigenous oral health, dental and social science researchers conducted a comprehensive four-phase case study to identify cultural competence curriculum interventions in dentistry education, provide a baseline investigation of Indigenous cultural competence curricula practices and ascertain barriers and enablers to integrating Indigenous cultural competence into dentistry programmes. The culmination of this research has resulted in the development of an Indigenous cultural competence model to assist dental education within Australian. Our research team established a Cultural Competence Curriculum Review Reference Group comprising Indigenous and non-Indigenous members. Indigenous and non-Indigenous research team and reference group members are engaged within the cultural interface at each phase of this research to facilitate culturally safe research practices and ensure authentication and validity of the data. The process of how we developed this model and the relationships built during this research is the focus of this chapter. How do Indigenous and non-Indigenous researchers work together to achieve positive outcomes?
\end{abstract}

Keywords Culture $\cdot$ Education $\cdot$ Dental $\cdot$ Oral health $\cdot$ Indigenous $\cdot$ Australia

C. Forsyth $(\bowtie) \cdot$ M. Irving

School of Dentistry, The University of Sydney, Sydney, NSW, Australia

e-mail: Cathryn.Forsyth@sydney.edu.au

S. D. Short · J. Gilroy

Faculty of Medicine and Health, The University of Sydney, Sydney, NSW, Australia

M. Tennant

International Research Collaborative, Oral Health and Equity, The University of Western

Australia, Perth, Australia

(C) The Author(s) 2020

J. Frawley et al. (eds.), Transforming Lives and Systems,

SpringerBriefs in Education, https://doi.org/10.1007/978-981-15-5351-6_5 


\section{Background}

Indigenous peoples within Australia experience higher mortality rates and carry the greatest burden of disease in terms of both general and oral health. Several closingthe-gap policies have failed to achieve significant improvements in health outcomes. Unacceptable disparities in health and disease continue to exist, leaving Indigenous Australians disadvantaged across a range of health indicators (Vos, Barker, \& Begg, 2009; Mitrou, Cook, \& Lawrence, 2014).

Several higher education reviews have identified the need for all tertiary institutions to incorporate Indigenous culture and knowledge more widely into all faculty curricula to improve educational outcomes for Indigenous Australians and to increase cultural competence among all students. In 2008, the Bradley 'Review of Australian Higher Education' recommended that higher education providers should ensure that the institutional culture, the cultural competence of staff and the nature of the curriculum recognise and support the participation of Indigenous students and that Indigenous knowledge should be embedded into the curriculum so that all students gain an understanding of Indigenous culture (Bradley, Noonan, Nugent, \& Scales, 2008). Universities Australia investigated existing Indigenous cultural competency initiatives and programmes in Australian universities to establish a clear baseline for Indigenous cultural competency activities. Subsequently, a National Best Practice Framework and Guiding Principles for Indigenous Cultural Competency in Australian Universities was developed (Universities Australia, 2011a, b). During 2012, the Behrendt Review of Higher Education Access and Outcomes for Aboriginal and Torres Strait Islander People, building on the Bradley Review, examined how improving higher education outcomes among Indigenous people would contribute to nation-building and reduce Indigenous disadvantage (Behrendt, Larkin, Griew, \& Kelly, 2012).

An Indigenous cultural competence curriculum framework for dental students was developed in 2007 by a team at the Centre for Rural and Remote Oral Health, and now the IRCOHE at the University of Western Australia (Bazen, Paul, \& Tennant, 2007). As the accreditation standards for dental schools at that time did not include mandatory Indigenous cultural curricula, the changes were not maintained. However, recent accreditation standards by the Australian Dental Council require all dentistry and oral health professionals within Australia to provide culturally safe and culturally competent practice that includes recognition of the distinct needs of Indigenous Australians in relation to oral healthcare provision (ADC, 2016).

As cultural competence gains momentum and is linked to regulatory and accreditation processes, it will be essential to develop nationally standardised educational programmes based on a unified conceptual teaching framework. In higher education, academics will be required to consider how best to train the future healthcare workforce, and cultural competence training for faculty members will be crucial to achieving research outcomes on cultural competence interventions (Bainbridge, McCalman, Clifford, \& Tsey, 2015). Indigenous people in Australia are significantly under-represented in the higher education and healthcare systems, which contributes 
to the high levels of social and economic disadvantage they often experience. Producing Indigenous graduates who are qualified to take up professional, academic and leadership positions within community, government and corporate sectors will help to address this disadvantage (Behrendt et al., 2012).

The Indigenous concept of health is holistic, with self-determination being central to the provision of Indigenous health services (Durie, 2014). A culturally valid understanding must shape provision of Indigenous healthcare, acknowledging experiences of trauma and loss have greatly contributed to the impairment of Indigenous culture, health and well-being (Dury \& Thompson, 2012). Recognition of existing colonial ways, power imbalances and dominant or oppressive policies within the healthcare system will aid in understanding Indigenous perspectives.

University curricula, teaching methodologies and research endeavours have a history of development that contributed to the dispossession of Indigenous people (Martin, 2003; Moreton-Robinson, Casey, \& Nicoll, 2008). Historical foundations of dentistry and oral health education and research in Australia have been developed in accordance with Western epistemology. Non-Indigenous researchers have considered Indigenous knowledge as second-rate describing themselves as the producers of knowledge (Moreton-Robinson, 2004). Medical, health and social sciences within Universities have focused on modern and industrialised concepts based on assumptions about the superiority of Western culture (Connell, 2007). Educational institutions, healthcare services and government departments have been established within colonial traditions, overtly and covertly supporting power, privilege and continuation of colonial ways. Indigenous peoples are often viewed as being problematic and costly, with media and history books providing Eurocentric viewpoints, consequently resulting in oppression and continuation of poor health outcomes (MoretonRobinson, 2004, 2008; Sherwood, 2009). It is paramount that Indigenous people are active participants in any Indigenous research, as Indigenous people have a level of experience and knowledge of colonisation and dispossession that a non-Indigenous person could not obtain (Tuhiwai-Smith, 1999; Esgin, Hersh, Rowley, Gilroy, \& Newton, 2018).

Complex issues surround the concept of cultural competence and the acute need for health practitioners to develop knowledge, skills, understandings and attributes to be responsive in diverse cultural settings. The human rights of Indigenous people must be recognised and enforced, with racism, adversity, stigma and social disadvantage, being addressed in strategies aimed at improving Indigenous health. The centrality and strength of Indigenous family and kinship must be understood, along with diversity of Indigenous people groups being recognised. We need to move beyond the traditional biomedical model of healthcare and embrace a holistic model of care encompassing a more culturally responsive, client-centred, holistic model of care (Dudgeon, Milroy, \& Walker, 2014).

Reflective practice is a major tool used within professional disciplines to assist in developing appropriate client-practitioner relationships, and encouraging practitioners to explore uncertainties and difficulties in our sense-making, to identify inconsistencies between what we think and what we do (Fook \& Gardner, 2007). 
Reflective practice encourages us to compare our current practices with new experiences, developing a deeper understanding of issues, motivating us to change over time (Prochaska, 1997). Critical self-reflection is a useful decolonising tool as it assists in questioning our assumptions, challenges our values and beliefs, and identifies individual and institutional practices that perpetuate racism and injustice (Harvey \& Russell-Mundine, 2019). In the next section we will explore how our team utilised Indigenous methodologies within our research, and in the final section our first author will share some reflections of her experiences in navigating this cultural interface.

\section{Use of Indigenous Methodologies Within Research}

A methodology that was appropriate for Indigenous people was designed with a working group that consisted of Indigenous Elders, Indigenous scholars and nonIndigenous scholars for this case study. Current frameworks in dental sciences were not appropriate for this case study as they fail to acknowledge the diversity within Indigenous lands and cultures and maintain dominant colonial ways. Employing Indigenous decolonisation methodologies provides a better understanding of particular motivations and behaviours within Indigenous communities, unearthing aspects which have not been previously explored. Each Indigenous community must be understood in the context of their experience of colonisation, disadvantage and cultural heritage (Gilroy, Donelly, Colmar, \& Parmenter, 2013).

Reflecting Indigenous methodologies, an Indigenous research governance model was employed, with this research team establishing a Cultural Competence Curriculum Review Reference Group in mid-2015, comprising Indigenous and nonIndigenous scholars and leaders. Collaborations between the reference group and our Indigenous and non-Indigenous dental, oral health and social scientific research team were ongoing. During development of the ethics application, our reference group was involved to ensure all researches conducted were in keeping with the National Health and Medical Research Council Guidelines (NHMRC, 2003, 2013). At each phase of data collection and analysis, the reference group and research team met to discuss research findings, supporting verification of all data and maximising authenticity of all data. Indigenous methodologies informed this entire research process.

Three fundamental principles were adopted when conducting this research. First, this research was counter-hegemonic to Western ideologies, strengthening and supporting the fight to alleviate social conditions that result in poor quality of life for Indigenous people. Secondly, this research privileged the Indigenous voice to depict various experiences of Indigenous people and ensure non-Indigenous populations are aware of the concerns and ambitions of Indigenous spokespeople. Thirdly, this research was conducted by Indigenous and non-Indigenous researchers (Foley, 2006; Rigney, 1999). The third point reinforces the notion that Indigenous people have a level of knowledge and experience that non-Indigenous researchers could not possibly acquire; hence Indigenous people need to be explicitly involved in any Indigenous 
research. Gilroy, an Indigenous sociologist, developed criteria for use in working with Indigenous peoples with disabilities. These criteria assisted researchers and policy advisors to develop research for and with Indigenous people with disabilities (Gilroy et al., 2013).

Indigenous methodologies identify power imbalances that have existed since colonisation and examine dominant and oppressive policy. Indigenous methodologies deconstruct myths or particular practices and respect Indigenous ways of knowing, being and doing, providing balanced views about Indigenous people's circumstances (Ganesharajah, 2009; Martin, 2003; Sherwood, 2009, 2013). Although many Indigenous elders and community members have participated actively in voicing their concerns about social justice and health issues, power differentials continue to exist resulting in the continuation of poor policy and service provision for Indigenous people. Indigenous people need to share their stories and provide an Indigenous perspective on social and health issues, to facilitate improvement in the health and wellbeing of Indigenous people (Sherwood, 2006).

This research team acknowledges other research methods used globally that are consistent with Indigenous methodologies such as Participatory Action Research (PAR) and Community Based Participatory Research (CBPR). PAR involves inquiry, reflection and action that aim to improve health and reduce health inequalities by embracing methodological approaches to hand over power from the researcher to the research participants. PAR complements the principles held by academic researchers in the fields of anthropology, social sciences, theology and community development (Bennett, 2004; Baum, MacDougall, \& Smith, 2006). CBPR integrates education and social action to improve health and reduce health disparities, focusing on building relationships between academics and community partners, through a long-term commitment, active participation and learning together in a spirit of reciprocity. Similar to Indigenous methodologies, CBPR challenges mutuality of the research relationship, especially around issues of power, privilege, community consent, racial discrimination and the role of research in affirmative social change (Wallerstein et al., 2006, 2010).

Our research team integrated Gilroy's criteria (Gilroy et al., 2013) throughout this research emphasising the importance of including Indigenous community within the research team to ensure equal distribution of power and responsibility. Colonisation has been recognised as a social determinant of health, with the research team being well-informed of colonial influences and the historical dispossession of Indigenous land, traditions and culture (Sherwood, 2013). Similarities and differences between Indigenous communities and understanding struggles faced by Indigenous communities to attain rights to be self-sustaining have been acknowledged. Indigenous and non-Indigenous research team members have met in this cultural interface, gaining a profound understanding of the issues at hand from each other. Together these criteria have empowered our Indigenous researcher and reference group members, improving relationships between Indigenous and non-Indigenous researchers.

Within this methodological framework the case study was conducted in four phases: First, a systematic search of the literature was undertaken in 2016 to identify studies on cultural competence curriculum interventions in dentistry and oral 
health higher education. Qualitative analysis was undertaken to explore in detail participants personal and educational experiences with cultural competence curricula (Forsyth, Irving, Tennant, Short, \& Gilroy, 2017a). Secondly, a survey involving all staff and students of the Doctor of Dental Medicine (DMD) and Bachelor of Oral Health (BOH) programs at the University of Sydney was conducted during 2017, to gather a snapshot of current Indigenous curricula practices in the respective courses (Forsyth et al., 2017b). Thirdly, all School of Dentistry academics and students from the DMD and $\mathrm{BOH}$ programmes were invited to participate in in-depth interviews to determine barriers and enablers to integrating Indigenous culture into dentistry and oral health curricula throughout 2018. Thematic analysis was performed using deductive and inductive processes. Our reference group collaborated at each phase of this research to discuss formulation of codes and themes and make sense of the data (Forsyth et al., 2018, 2019). Fourthly, an Indigenous cultural curriculum model was developed in 2019 to assist in the integration of Indigenous curricula for all dental and oral health schools in Australia. Effective Indigenous cultural curricula in dentistry and oral health education will facilitate an improvement in the delivery of oral health services to Australia's Indigenous peoples and have a positive impact on the general health of Australian Indigenous peoples.

Indigenous people are entwined within this much contested knowledge space referred to as the 'cultural interface' (Nakata, 2004). This cultural interface is the sphere where two different histories, cultures, philosophies and practices intersect, creating environments that influence the way Indigenous peoples make sense of and participate in society. As Indigenous and non-Indigenous people socialise within this interface, a greater level of understanding of Indigenous issues result; however as there are so many conflicting and competing discourses that distinguish traditional from non-traditional, this interface will always be distorted. The theory of the cultural interface illuminates difficulties in sharing and interpreting knowledge between Indigenous and non-Indigenous people. This is often due to a focus on difference rather than facilitating an understanding of the meaning of knowledges from both sides. Examining differences between cultural groups ignores the existence of the cultural interface as it does not deconstruct Western epistemologies; rather it upholds Indigenous people as helpless victims of colonisation and establishes power relationships in favour of non-Indigenous people. The theory of the cultural interface requires breaking away from 'us' and 'them' and critiquing how interactions at the cultural interface reinforce non-Indigenous culture as dominant in the Australian political system and hence in the healthcare system. Indigenous people distrust institutions managed by non-Indigenous people due to past experiences of forced removal of children and Indigenous assimilation policies (Nakata, 2004).

\section{Personal Reflection of First Author}

As a non-Indigenous clinician and researcher, my Indigenous cultural competency journey commenced as a child with my Indigenous friend in primary school, who was adopted by a non-Indigenous family in the early 1970s. Our families spent time 
together outside of school. I learnt several years later that my friend had attempted to reconnect with her Indigenous family and struggled for several years before passing away. This greatly affected me and prompted many questions. It was not until I commenced work at the University of Sydney in 2005 that I was provided with this unique opportunity to work alongside Indigenous academics and professional staff and learn more about the difficulties my friend would have experienced.

Whilst attending an Indigenous Oral Health Conference at Uluru in remote Central Australia in 2005, I became more acutely aware of the significant disadvantages experienced by Indigenous Australians. Following this conference, I reflected on what we can do differently within Sydney Dental School to address this oral health disadvantage. Consequently, I built relationships with local Indigenous health workers to form partnerships for future student oral health prevention and health promotion projects. Initial engagement with the Mt Druitt Aboriginal Health Unit was helpful in developing the inaugural Bachelor of Oral Health (BOH) student project in 2007. I was invited to attend several Sorry Day events with this Unit, and my undergraduate students have been involved in numerous celebrations organised by the National Aborigines and Islanders Day Observance Committee (NAIDOC), with student oral health projects continuing to this day. During this time, I continued to reflect on my own experiences, realising how much my life has been one of power and privilege. I appreciated hearing the stories of my Indigenous colleagues and continued to grow in my understanding of why health and education disparities still exist. My knowledge and attitudes were changing and as a result of these relationships, I was able to establish my Indigenous Reference Group for this research project, as described below.

Throughout 2009-10, I completed my Master of Education in Higher Education and Research Methodology. During this time, I had the welcome opportunity to conduct a higher education research project with two Indigenous academics, Dr. John Evans and Dr Katrina Thorpe. This not only increased my understanding of qualitative research methods, but allowed me to share life with two capable and active Indigenous academics. My first Indigenous BOH student commenced in 2009 and completed an oral health promotion programme with Indigenous 'Mums and Bubs' in Albury prior to graduating in 2012. This inaugural BOH program generated greater understanding of Indigenous culture for me and facilitated opportunities to develop additional oral health promotion programs for future $\mathrm{BOH}$ students within Indigenous communities.

A Kinship Workshop facilitated by Dr Lynette Riley, a Wiradjuri and Gamilaroi woman and academic at the University of Sydney, was conducted in 2012. My involvement in this workshop not only increased my knowledge and understanding of Aboriginal history and culture but was instrumental in forming relationships with other University of Sydney academics, who were either Indigenous or people with an interest in Indigenous issues. I am still in regular contact with many whom I met at this workshop.

Since 2013, I have valued working with various Indigenous teams across the university, each with different perspectives. The Poche Centre for Indigenous Health has collaborated with the Sydney Dental School to develop a comprehensive oral 
health programme in the Central Tablelands region of New South Wales. I have been privileged to liaise with Poche team members in the University of Sydney as well as conduct field trips to the Central Tablelands in preparation for Bachelor of Oral Health (BOH) and Doctor of Dental Medicine (DMD) student programs. It is through this collaboration and local contact with Blacktown Department of Technical and Further Education and the Mana Yura student support services that an effective Indigenous student recruitment and retention policy for the $\mathrm{BOH}$ and $\mathrm{DMD}$ programs was developed. As a result, we have had another three Indigenous students complete the $\mathrm{BOH}$ program and another two Indigenous students are currently enrolled in the $\mathrm{BOH}$ program. My first Indigenous $\mathrm{BOH}$ graduate has been employed as a part-time clinical educator over the past three years and I have had the privilege of supervising her to completion of her Master of Education in 2017. This student is now preparing to commence the Doctor of Dentistry program in 2020.

I have also had the privilege of working with the Wingara Mura Bunga Barrabugu Indigenous strategy team, led by the Deputy Vice Chancellor (Indigenous Strategy and Service) at the University of Sydney. This has involved Indigenous camps and day programmes run by the Widening Participation unit throughout the University calendar year to provide opportunity for Indigenous school students to experience university life. Furthermore, the National Centre for Cultural Competence (NCCC) at the University of Sydney conducted a leadership training programme at Murramarang National Park, which provided an excellent opportunity to be immersed in Indigenous culture and form relationships with other academic and professional staff within the University. I have been involved in regular network meetings and include online modules developed by the NCCC in dental and oral health curricula (Sherwood \& Russell-Mundine, 2017).

Sharing in conversations with Indigenous academics, professional staff and students over several years has helped me to understand the importance of selfdetermination for Indigenous peoples. In the past, my historical understanding of Australia has been presented to me through the eyes of colonists. It is only as Indigenous colleagues are able to voice their concerns and present history from their perspective that we can truly work within this cultural interface and achieve reconciliation.

Following the appointment of my 'Dream Team', John Gilroy and I met to discuss the formation of an Indigenous Reference Group with Indigenous and nonIndigenous participants. As I had ongoing contact with local Indigenous community health professionals, I invited two of these-my $\mathrm{BOH}$ Indigenous graduate and a non-Indigenous DMD clinical educator-to join this reference group to meet twice each year. During reference group meetings, I learnt much about the effects of colonisation on Indigenous Australians and how many policies and actions are based on colonial ways. Additionally, I learnt how to approach meetings in a more culturally sensitive manner and identified my own cultural stereotypes and biases. Throughout reference group meetings, I presented findings from each phase of my research and gained significant insight as we viewed these from an Indigenous perspective.

Despite good intentions, there have been many occasions on which the nonIndigenous members of the research team have learnt from our Indigenous researcher and Cultural Competence Curriculum Review Reference Group members. At our 
first Cultural Competence Curriculum Review Reference Group meeting in 2015, I attempted to be culturally sensitive, welcoming members on arrival and arranging the seating in a circle. Although I knew each person in the meeting, I was aware others had not yet met, so I asked them to introduce themselves before asking our eldest Indigenous member to acknowledge country. When it came turn for our eldest Indigenous member to introduce herself, she stopped, mentioned the correct protocol for acknowledging country before any introductions, and acknowledged country before proceeding with the meeting agenda. On another occasion, when our team was starting to analyse data from the student in-depth interviews, our Indigenous researcher, Dr John Gilroy, randomly selected a few to analyse and found considerable use of the language of 'us' and 'them' throughout the interviews. Initially, I and other non-Indigenous members of the team did not recognise the use of such language. It was not until our Indigenous sociologist brought this to our attention that we were able to recognise the use of such language and gain insight into its historical use by the dominant western culture.

In the final phase of this research, I was attempting to incorporate how we utilised Indigenous methodologies as the conceptual framework for the entire case study. Although I thought I had done a reasonable job of including Indigenous methodologies content in my thesis, it was not until John Gilroy had a long discussion with me and suggested further reading that I understood I had not fully expressed this and that I lacked evidence of my research process. It was during this time of deliberation and reflection that I realised the extent to which my research team and reference group were intertwined in an Indigenous and non-Indigenous cultural interface, building bridges between Indigenous and non-Indigenous academics and healthcare workers, gaining greater understanding of each other and responding to challenges that emerged.

As a result of my research journey, I have gained much insight into historical and contemporary power differentials, privilege position and racism that have impacted upon the health and wellbeing of Indigenous Australians. It is only as Indigenous and non-Indigenous researchers and community members work together, that a greater understanding of Indigenous ways of knowing, being and doing can be understood, empowering the Indigenous voice, to ensure all research endeavours result in positive outcomes for Indigenous peoples.

In May 2019 Professor Heiko Spallek, my Dean, asked if I could prepare a response to the Australian Health Practitioners Regulation Agency (AHPRA) consultation on the definition of cultural safety on behalf of Sydney Dental School. As a result of my research experiences, I was able to develop an initial response to send to the Deputy Vice Chancellor (Indigenous Strategy and Services) and Associate Dean (Indigenous Strategy and Services) Faculty of Medicine and Health, for their feedback. After reflecting on their feedback my response was warmly received. This was a valuable learning experience in utilising my growing knowledge of Indigenous cultural competence in dentistry education and translating this knowledge into other contexts. Building positive professional relationships has been vital in navigating the cultural interface as a non-Indigenous person. I intend to use these positive relationships to pave the way for necessary change within dentistry and oral health 
education, to improve oral health outcomes for Indigenous Australians and promote reconciliation between Indigenous and non-Indigenous people within Australia.

\section{Conclusion}

Indigenous research conducted by Indigenous and non-Indigenous researchers is effective in building positive relationships to navigate the cultural interface. This research team established a Cultural Competence Curriculum Review Reference Group comprising Indigenous and non-Indigenous members. Reference group and research team members collaborated within the cultural interface at each phase of this research resulting in culturally safe research practices and authentication and validity of the data, to develop a model to integrate Indigenous culture into dentistry curricula. As Indigenous and non-Indigenous researchers functioned together to achieve significant research outcomes, a greater respect for one another resulted facilitating reconciliation between Indigenous and non-Indigenous team members. It is imperative that non-Indigenous researchers explicitly involve Indigenous researchers and Indigenous community members in Indigenous research to safeguard power distribution and ensure a culturally safe working environment, to achieve positive research outcomes as Indigenous people have a level of knowledge and experience that non-Indigenous researchers could not possibly acquire.

Acknowledgments The authors acknowledge the invaluable contribution of the Cultural Competence Curriculum Review Reference Group: Linda Lewis, Aboriginal Otitis Media Coordinator, WSLHD; Boe Rambaldini, Director, Poche Centre for Indigenous Health, University of Sydney; Jacinda Stamenkovic, Aboriginal graduate of the Bachelor in Oral Health program and Clinical Educator; Dr Nigel Rock, Doctor of Dental Medicine Clinical Educator, University of Sydney; and Professor Heiko Spallek, Head of School and Dean, Sydney Dental School, University of Sydney. They thank Bettina Fulham, for her dedication as our Research Administrative Assistant.

\section{References}

Australian Dental Council. (2016). Professional competencies of the newly qualified dentist. Retrieved from https://www.adc.org.au/sites/default/files/Media_Libraries/PDF/Accreditation/ Professional\%20Competencies\%20of\%20the\%20Newly\%20Qualified\%20Dentist_rebrand. pdf.

AHPRA Cultural Safety Consultation. (2019). Retrieved from https://www.ahpra.gov.au/News/ 2019-04-03-cultural-safety.aspx.

Bainbridge, R., McCalman, J., Clifford, A., \& Tsey, K. (2015). Cultural competency in the delivery of health services for Indigenous people. Canberra: Closing the Gap Clearinghouse.

Baum, F., MacDougall, C., \& Smith, D. (2006). Participatory action research. Journal of Epidemiology and Community Health, 60(10), 854-857. https://doi.org/10.1136/jech.2004.028662.

Bazen, J., Paul, D., \& Tennant, M. (2007). An Aboriginal and Torres Strait Islander oral health curriculum framework: Development experiences in Western Australia. Australian Dentist Journal, $52(2), 86-92$. 
Behrendt, L., Larkin, S., Griew, R., \& Kelly, P. (2012). Review of higher education access and outcomes for Aboriginal and Torres Strait Islander people final report. Canberra: AGPS.

Bennett, M. (2004). A review of the literature on the benefits and drawbacks of participatory action research. First Peoples Child \& Family Review, 1(1), 19-32.

Bradley, D., Noonan, P., Nugent, H., \& Scales, B. (2008). Review of Australian Higher Education Final Report. Canberra, ACT: Department of Education, Employment and Workplace Relations.

Connell, R. (2007). Southern Theory: The global dynamics of knowledge in the social sciences. Crows Nest, NSW: Allen \& Unwin.

Dudgeon, P., Milroy, H., \& Walker, R. (2014). Working together: Aboriginal and Torres Strait Islander mental health and wellbeing principles and practice. Canberra: Commonwealth of Australia.

Durie, M. (2014). Understanding health and illness: research at the interface between science and indigenous knowledge. International Journal of Epidemiology, 33, 1138-1143.

Dury, A., \& Thompson, S. (2012). Reducing the health disparities of Indigenous Australians: Time to change focus. BMC Health Services Research, 12, 151.

Esgin, T., Hersh, D., Rowley, K., Gilroy, J., \& Newton, R. (2018). Indigenous research methodologies: decolonizing the Australian sports sciences. Health promotion international, https://doi. org/10.1093/heapro/day076.

Foley, D. (2006). Indigenous standpoint theory: An acceptable academic research process for Indigenous academics. International Journal of the Humanities, 3(4), 25-36.

Fook, J., \& Gardner, F. (2007). Practising critical reflection: A resource handbook (p. 2007). Berkshire: Open University Press.

Forsyth, C. J., Irving, M. J., Tennant, M., Short, S. D., \& Gilroy, J. A. (2017a). Teaching cultural competence in dental education: A systematic review and exploration of implications for Indigenous populations in Australia. Journal of Dental Education, 81, 956-968.

Forsyth, C. J., Irving, M. J., Tennant, M., Short, S. D., \& Gilroy, J. A. (2017b). Indigenous cultural competence: A dental faculty curriculum review. European Journal of Dental Education, https:// doi.org/10.1111/eje.12320.

Forsyth, C. J., Irving, M. J., Short, S. D., Tennant, M., \& Gilroy J. A. (2018). Strengthening Indigenous cultural competence in dentistry and oral health education: Academic perspectives. European Journal of Dental Education, https://doi.org/10.1111/eje.12398.

Forsyth, C. J., Irving, M. J., Short, S. D., Tennant, M., \& Gilroy, J. A. (2019). Students don't know what they don't know: Dental and oral health students' perspectives on developing cultural competence regarding Indigenous peoples. Journal of Dental Education, 83(6), 679-686.

Ganesharajah, C. (2009). Indigenous health and wellbeing: The importance of country. Canberra, ACT: Australian Institute of Aboriginal and Torres Strait Islander Studies.

Gilroy, J., Donelly, M., Colmar, S., \& Parmenter, T. (2013). Conceptual framework for policy and research development with Indigenous people with a disability. Australian Aboriginal Studies, 2, $42-58$.

Harvey, A., \& Russell-Mundine, G. (2019). Decolonising the curriculum: using graduate qualities to embed Indigenous knowledges at the academic cultural interface. Teaching in Higher Education, 24(6), 789-808.

Martin, K. (2003). Ways of knowing, ways of being and ways of doing: a theoretical framework and methods for Indigenous research and Indigenist research. Journal of Australian Studies, 76, 203-214.

Mitrou, F., Cook, M., \& Lawrence, D. (2014). Gaps in Indigenous disadvantage not closing: A census cohort study of social determinants of health in Australia, Canada, \& New Zealand from 1981 to 2006. BMC Public Health, 14, 201.

Moreton-Robinson, A. (2004). Whiteness, epistemology and Indigenous representation. In A. Moreton-Robinson (Ed.), Whitening race: Essays in social and cultural criticism (pp. 75-88). Canberra: Aboriginal Studies Press.

Moreton-Robinson, A., Casey, M., \& Nicoll, F. (2008). Transnational whiteness matters. Lanham, MD: Lexington Books.

NAIDOC History. (n.d.). Retrieved from https://www.naidoc.org.au/about/history. 
Nakata, M. (2004). Indigenous knowledge and the cultural interface: underlying issues at the intersection of knowledge and information systems. IFLA Journal, 28(5-6), 281-291.

National Health and Medical Research Council. (2003). Values and ethics: Guidelines for ethical conduct in Aboriginal and Torres Strait Islander health research. Canberra: Australian Government Publishing.

National Health and Medical Research Council. (2013). Guidelines for research into Aboriginal health: Key principles. Sydney: Aboriginal Health \& Medical Research Council of NSW.

Prochaska, J. O., \& Velicer, W. F. (1997). The Transtheoretical model of health behavior change. American Journal of Health Promotion, 12(1), 38-48.

Riley, L. (n.d.). Kinship modules. Retrieved from https://sydney.edu.au/about-us/vision-and-values/ our-aboriginal-and-torres-strait-islander-community/kinship-module.html.

Rigney, L. (1999). Internationalisation of an Indigenous anticolonial cultural critique of research methodologies: A guide to Indigenist research methodology and its principles. Wicazo SA Review, Autumn, 12.

Sherwood, J., \& Edwards, T. (2006). Decolonisation: A critical step for improving Aboriginal health. Contemporary Nursing, 22, 178-190.

Sherwood, J. (2009). Who is not coping with colonization? Laying out the map for decolonization. Australasian Psychiatry, https://doi.org/10.1080/10398560902948662.

Sherwood, J. (2013). Colonisation-It's bad for your health: The context of Aboriginal health. Contemporary Nurse, 46(1), 28-40.

Sherwood, J., \& Russell-Mundine, G. (2017). How we do business: Setting the agenda for cultural competence at the University of Sydney. In J. Frawley, S. Larkin, \& J. A. Smith (Eds.), Indigenous pathways, transitions and participation in higher education. Springer Open: Singapore.

Tuhiwai-Smith, L. (1999). Decolonising methodologies: Research and Indigenous peoples. Dunedin: University of Otago Press.

Australia, U. (2011a). National best practice framework for Indigenous cultural competence. Canberra, ACT: Universities Australia.

Australia, U. (2011b). Guiding principles for developing Indigenous cultural competence in Australian universities. Canberra, ACT: Universities Australia.

Wallerstein, N., \& Duran, B. (2006). Using community-based participatory research to address health disparities. Health Promotion Practice, 7(3), 312-323. https://doi.org/10.1177/ 1524839906289376.

Wallerstein, N., \& Duran, B. (2010). Community-based participatory research contributions to intervention research: The intersection of science and practice to improve health equity. American Journal of Public Health, Supplement 1, 100(S1).

Vos, T., Barker, B., \& Begg, S. (2009). Burden of disease and injury in Aboriginal and Torres Strait Islander people: The Indigenous health gap. International Journal of Epidemiology, 38, 470-477.

Open Access This chapter is licensed under the terms of the Creative Commons Attribution 4.0 International License (http://creativecommons.org/licenses/by/4.0/), which permits use, sharing, adaptation, distribution and reproduction in any medium or format, as long as you give appropriate credit to the original author(s) and the source, provide a link to the Creative Commons license and indicate if changes were made.

The images or other third party material in this chapter are included in the chapter's Creative Commons license, unless indicated otherwise in a credit line to the material. If material is not included in the chapter's Creative Commons license and your intended use is not permitted by statutory regulation or exceeds the permitted use, you will need to obtain permission directly from the copyright holder.

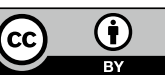

